size of the fundus, especially if there has been a previous history of acute inflammation. A preliminary examination of the nasal passages is advisable and if necessary any obstruction due to deflection of the septum should be corrected.

\title{
Summary
}

This describes a simple method of keeping a graft from the lacrymal sac in position in external dacryocystorhinostomy and requires the use of no special instruments other than those provided in the equipment of a Military Hospital.

The use of rubber tubing is introduced to do this (tube drainage of the frontal sinus into the nose is a common procedure and suggested its employment in these cases).

Dacryocystitis, although not a dangerous, condition, can cause much inconvenience and any treatment which can alleviate its symptoms has a useful place in surgical procedures, particularly if of a simple nature and requiring no special equipment.

\section{A CASE OF CORPORA NIGRA WITH ANTERIOR SYNECHIA*}

\author{
BY \\ ROBERT CRAWFORD \\ ROXXL LOXDON OFHTHAL MIC HOSPITAL
}

A MAN aged 25 years was recently seen at this hospital; he had never noticed anything strange about his eyes until he complained of dazzling of the left eye in bright sunlight.

He shows in both irides large flocculi or corpora nigra, more marked in the left eye than the right. They are larger on the upper border than the lower, and are not, seen along the nasal and temporal sides, following the usual arrangement (Stahli). The especial feature of this case is that one of the upper corpora nigra in the left eye is attached to the back of the cornea. I have been unable to find any reference to this condition in the literature or on personal enquiry, and, subject to correction, believe it to be unique. The flocculus appears to be truly attached to the cornea, not merely lying against it, over a flattened area of some two millimetres diameter, whose position and size remain constant whether the pupil is normal or dilated. The flocculus gives the impression also of being slightly stretched. Near its corneal end it is bifurcated, but the end itself is single. There is no loose pigment in the anterior chamber, which is clear and of normal depth.

\footnotetext{
* Received for publication, March 1, 1944.
} 


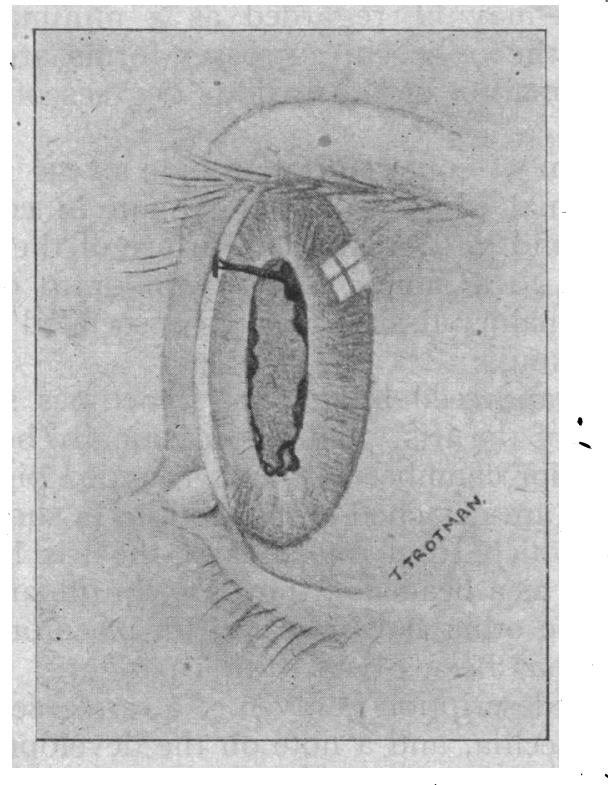

The irides react sluggishly to light and accommodation, which, together with the dazzling due to the anterior synechia, accounts for the patient's difficulty in bright light. The eyes are otherwise normal and clear on transillumination. The vision is right $6 / 6$, and left $6 / 12$, improved to $6 / 9$.

Corpora nigra are seen not infrequently in man, and are of the same origin as those found normally in the horse, sheep, pig, goat and other ungulates. They are dilated portions of the marginal sinus. In the development of the eye invagination of the primary optic vesicle forms the optic cup, which is doublewalled. Before the third foetal month the two layers of the optic cup are separated: as the two layers unite, the portion around the rim of the cup remains patent, forming the marginal sinus. It is at first very small, but as the iris develops it increases in size until five months; after this it begins to diminish and is closed at seven months.

This is the normal in man, but sometimes the sinus does not close, and instead becomes dilated into cysts. These flocculi are probably merely dilatations of the normal serrations of the pigmented.iris margin : in some cases they are divided up by definite bands, which are strands from the mesoderm of the pupillary membrane.

It is suggested that in this patient one of the flocculi passed through the pupillary membrane about the fifth month, when the marginal sinus is well developed and the anterior chamber is still shallow, and became adherent to the cornea. 
The condition may be regarded as a minimal form of mal- development of the optic cup; grosser forms are known, which result in the formation of the various degrees of congenital cyst of the eye.

The other form of congenital ectropion uveae is that in which the two ectodermal pigment layers remain in contact but come to lie further round on the anterior surface of the iris than usual. This is ascribed to a simple overgrowth or to dragging of the layers by inflammatory tissue; it is not associated with persistence of the marginal sinus.

Very small grape seed bodies are sometimes seen around the pigment border of the iris. These occasionally become loose and float in the anterior chamber as small, rounded pigmented bodies. That they really are detached corpora nigra is shown by a case of Dymschitz, in which from one half of the iris border they had become detached as a beaded string lying in the anterior chamber, while those of the other half were still in place on the iris.

No treatment has been given to this' patient.

Summary.-A description is given of a rare case of iris flocculus with anterior synechia, and a note on the development of flocculi.

\title{
REFERENCES
}

DYMSchiтz.-Arch.f. Ophthal., Vol. CXXVII, 1931.

MANN.-Development of the Human Eye. Cambridge University Press. 1928.

Developmental Abnormalities of the Eye. Cambridge University Press. 1937.

REIS.-Zeitschr.f. Augenheilk., Vol. XXII, 1909.

STAHLI.-Klin. Monatsbl. f. Augenheilk., Vol. LXV, 1920.

VOGT,-Atlas d.Spaltlampenmikroscopie. Berlin.. 1931.

\section{UNILATERAL MEMBRANOUS CONJUNCTIVITIS, WITH COMPLETE CAST* .}

\author{
BY \\ J. F. GALPINE \\ MEDICÁL SUPERINTENDENT, CITY ISOLATION \\ HOSPITAL, COVENTRY \\ and \\ DOROTHY R. CAMPBELL \\ OPHTHALMIC SURGEON, COVENTRY AND \\ - WARWICKSHIRE HOSPITAL
}

THE patient was a girl of six years old, admitted to the City Isolation Hospital on October 11, 1942, with a moderate attack of scarlet fever. The rash was well marked and the throat was injected, with rather extensive semi-confluent follicular exudates on

* Received for publication, June 1, 1944. 